\title{
PENGARUH PSIKOLOGI KOMBINASI WARNA DALAM WEBSITE
}

\author{
Auria Farantika Yogananti \\ Program Studi Desain Komunikasi Visual \\ Fakultas Ilmu Komputer, Universitas Dian Nuswantoro Semarang \\ yogananti.au@dsn.dinus.ac.id
}

\begin{abstract}
Abstrak
Website terdiri dari dua hal penting, yang terlihat dan yang tak terlihat. Hal yang terlihat adalah user interface. Warna merupakan salah satu hal yang bertanggung jawab pada sebuah interface [1]. Sehingga untuk membuat sebuah website pemilihan terhadap warna sangat penting. Hal ini juga dikuatkan oleh Institut untuk research warna dalam Krischer disampaikan bahwa user memberikan penilaian dibawah sadar terhadap website dalam waktu 90 detik, dan 90\% penilaian berdasar pada warna [3]. Dengan menggunakan metode deskriptif kualitatif data-data yang didapat dari studi literatur mengenai teori psikologi warna Goethe dan Itten dipetakan kedalam teori kombinasi warna sehingga didapat kesan yang muncul dari psikologi kombinasi warna pada website.
\end{abstract}

Kata Kunci: psikologi warna, kombinasi warna, website

\section{PENDAHULUAN}

Website tentu sudah tidak asing lagi bagi kebanyakan orang karena website sekarang digunakan untuk banyak kepentingan mulai dari kepentingan pribadi hingga kepentingan corporate. Website sendiri dibangun dari dua hal penting, 'yang tidak dapat dilihat secara langsung' oleh user dan 'yang dapat terlihat secara langsung' oleh user. Coding yang membangun sebuah website merupakan hal yang tidak dapat dilihat secara langsung oleh user sedangkan tampilan user interface merupakan hal yang dapat dilihat langsung oleh user.

User Interface tidak lepas dari komponen desain, komponen yang memberikan keindahan pada tampilan sebuah website. Komponen desain dibentuk dari beberapa unsur seperti Layout and Composition, Color, Texture, Typography, dan Imagery. Setiap unsur memiliki tanggung jawab yang berbeda dalam sebuah website seperti Layout and Composition yang bertanggung jawab pada tata letak. Color bertanggung jawab pada estetika dan identitas website, Texture bertanggung jawab pada tampilan yang khas pada permukaan sebuah website, Typography bertanggung jawab pada penyampaian informasi, serta imagery yang bertanggung jawab pada perwujudan tampilan gambar dari informasi yang sampaikan [1]

Warna sebagai komponen yang bertanggung jawab pada estetika dan identitas sebuah website, menjadikan warna sebagai salah satu komponen yang sangat penting dalam sebuah website. Warna pada dasarnya adalah suatu peristiwa sensorik, sebuah respon fisiologis dari sebuah rangsangan cahaya. Namun tidak hanya itu saja, warna juga dapat digunakan untuk mengekspresikan emosi sehingga dapat menjadi sebuah bahasa non verbal yang dapat mengkominukasikan ide tanpa kata-kata [1]. Warna 
digunakan tentunya adalah semua warna yang ada, tidak hanya penggunaan satu warna namun juga kombinasi beberapa warna. Menurut Flavian dalam Pratama, Warna dalam hal ini perpaduan warna merupakan salah satu faktor kesuksesan sebuah website [2]. Sehingga untuk membuat sebuah website pemilihan terhadap warna sangat penting. Hal ini juga dikuatkan oleh Institut untuk research warna dalam Krischer disampaikan bahwa user memberikan penilaian dibawah sadar terhadap website dalam waktu 90 detik, dan $90 \%$ penilaian berdasar pada warna [3].

\section{METODE}

Metode yang digunakan adalah metode deskriptif kualitatif dengan menggunakan data-data yang didapat dari studi pustaka yang berkaitan dengan teori warna dan teori psikologi warna. Tahapan yang dilakukan adalah mengetahui terlebih dahulu psikologi warna dari teori yang dikemukakan oleh Johann Wolfgang Von Goethe, Johannes Itten, kemudian analisa dilakukan dengan cara membandingkan psikologi warna yang ada dengan teori kombinasi warna pada lingkaran warna yang ada pada color wheel pro.

\section{TINJAUAN PUSTAKA}

Ada banyak hal yang dapat di bicarakan dari sebuah teori warna karena pada dasarnya Teori warna adalah prinsip-prinsip yang digunakan untuk menciptakan harmonisasi dari kombinasi pada sebuah warna. Lingkaran warna dan harmoni dari kombinasi warna adalah dua hal yang dapat dipelajari dari teori warna.

Sebelum ditemukannya lingkaran warna, penjelasan mengenai warna sering dipaparkan dalam bentuk linear atau garis seperti yang dibuat oleh pythagoras dan aristoteles. Namun Newton membuat terobosan baru setelah menemukan pembiasan cahaya pada sebuah prisma, ia memenyatukan warna awal dan akhir dari hasil pembiasan cahaya yang ada menjadi sebuah lingkaran warna. Seratus tahun berselang setelah Newton membuat lingkaran warnanya, Johann Wolfgang von Goethe membuat lingkaran warna dengan menggunakan tiga warna primer yaitu merah, biru dan kuning dan menambahkan warna turunannya yaitu ungu, hijau dan orange diantara warna primer. Lingkaran warna Goethe sering dijadikan acuan untuk dunia desain. Lingkaran warna ini pula kemudian berkembang dengan memasukkan warna tersier kedalam lingkaran warna sehingga dalam satu lingkaran terdapat warna primer, sekunder dan tersier. Tidak hanya berhenti disitu, lingkaran warna terus berkembang kedalam bentuk tiga dimensional yang juga memadukan unsur gelap dan terang seperti lingkaran warna yang dibuat oleh Albert Henry Munsell.

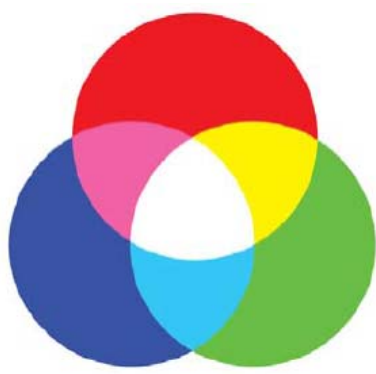

Gambar 1. Warna Additive

Tidak hanya berhenti disitu, lingkaran warna terus berkembang kedalam bentuk tiga dimensional yang juga memadukan unsur gelap dan terang seperti lingkaran warna yang dibuat oleh Albert Henry Munsell [4]. Warna yang digunakan pada website merupakan warna yang ditampilkan pada monitor sehingga warna yang digunakan merupakan warna additive atau yang biasa disebut warna cahaya [5]. Warna cahaya dapat dilihat pada gambar 1 


\subsection{Teori Kombinasi Warna}

Ada banyak hal yang dapat di bicarakan dari sebuah teori warna karena pada dasarnya Teori warna adalah prinsip-prinsip yang digunakan untuk menciptakan harmonisasi dari kombinasi pada sebuah warna karena lingkaran warna dan harmoni adalah dua hal yang dapat dipelajari dari teori warna.

Kombinasi warna diperlukan untuk mendapatkan komposisi yang berbeda pada sebuah karya. Namun kita memerlukan kombinasi yang baik sehingga kita dapat menghasilkan sebuah harmoni warna. Harmoni warna terjadi karena adanya keserasian pada saat dua atau beberapa warna berinteraksi satu sama lain. Komposisi warna akan sangat berkaitan dengan efek yang ditimbulkan pada saat orang melihat warna-warna tersebut, sehingga efek yang ditimbulkan akan memiliki banyak kemungkinan seperti enak dilihat ataupun tidak enak dilihat. Dae Young Kim menyatakan bahwa fullcolours lebih efektif dibandingkan dengan dua macam warna [6]. Sehingga Kombinasi warna yang digunakan adalah kombinasi yang terdiri dari 3 warna atau lebih. Berikut beberapa kombinasi warna yang sering digunakan menurut Color wheel pro : [7]

1. Kombinasi Split complementary

Kombinasi ini terdiri dari 3 warna yaitu satu warna dan dua warna yang berlawanan yang menyabar. Bila dilihat kombinasi warna ini akan menyerupai segitiga sama kaki.

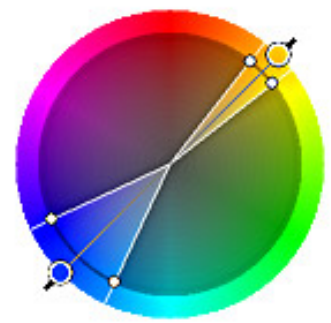

Gambar 2. Kombinasi Split complementary

2. Kombinasi Triadic

Kombinasi ini terdiri dari 3 warna yaitu satu warna dan dua warna berlawanan yang menyabar sama lebar. Bila dilihat kombinasi warna ini akan menyerupai segitiga sama sisi sehingga kombinasi warna ini terlihat lebih seimbang.

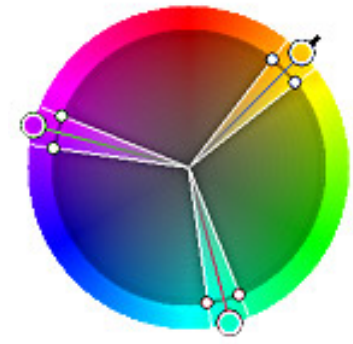

Gambar 3. Kombinasi Triadic 
3. Kombinasi Tetradic (double complementary)

Kombinasi tetradic (double complementary) terdiri 4 warna . 4 warna ini berasal dari sepasang dua warna yang berlawanan. Kombinasi ini lebih sulit di kombinasikan dengan jumlah yang seimbang sehingga pembagian warna harus dirancang.

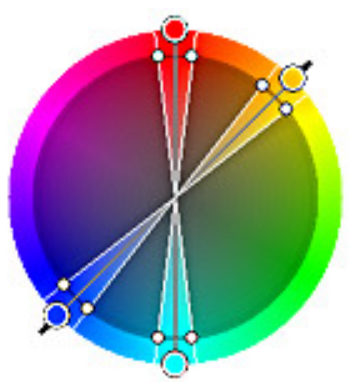

Gambar 4. Kombinasi Tetradic (double complementary)

\subsection{PSIKOLOGI WARNA}

A. Johann Wolfgang von Goethe

Psikologi warna dapat kita pahami salah satunya dengan mengetahui perlambangan warna. Perlambangan warna akan berbeda pada setiap budaya dan masa dimana setiap penemu ada. Nijdam menuliskan bahwa dalam bukunya Theory of Colours, Goethe menyatakan bahwa setiap warna memberikan kesan yang positif dan kesan yang negatif yang berpengaruh pada emosi [8] . Warna yang memberikan kesan positif adalah kuning, sedangkan warna yang lebih memberikan kesan negatif adalah biru seperti yang terlihat pada tabel berikut:

Tabel 1. Psikologi warna Goethe

\begin{tabular}{|c|c|c|c|}
\hline Warna & Kesan Positif & Kesan Negatif & $\begin{array}{c}\text { Pengaruh } \\
\text { terhadap } \\
\text { Emosi }\end{array}$ \\
\hline Kuning & $\begin{array}{l}\text { Cepat, } \\
\text { Ceria }\end{array}$ & Tidak menyenangkan & \multirow{3}{*}{$\begin{array}{l}\text { Menimbulkan } \\
\text { efek sukacita }\end{array}$} \\
\hline Kuning-Merah & $\begin{array}{c}\text { Hidup, } \\
\text { Passion yang tinggi }\end{array}$ & Menjengkelkan & \\
\hline Merah Kuning & $\begin{array}{c}\text { Hangat, } \\
\text { Sukacita/Kegembiraan }\end{array}$ & & \\
\hline Biru & Warna yang menyenangkan & $\begin{array}{l}\text { Dingin, } \\
\text { Melankolis } \\
\text { Gelisah }\end{array}$ & \multirow{3}{*}{$\begin{array}{c}\text { Menimbulkan } \\
\text { efek Sedih }\end{array}$} \\
\hline Merah Biru & aktif & Rentan & \\
\hline Biru-Merah & aktif & Cemas & \\
\hline Merah & Bermartabat & & $\begin{array}{l}\text { Menimbulkan } \\
\text { efek semangat }\end{array}$ \\
\hline Hijau & Tenang & & $\begin{array}{l}\text { Menimbulkan } \\
\text { efek Tenang }\end{array}$ \\
\hline
\end{tabular}


B. Johannes Itten

Dalam Bukunya The elements of color [9], Itten menyatakan bahwa warna memberikan kesan dan efek yang berbeda terhadap manusia. Warna dapat memberikan efek sebagai berikut:

$\begin{array}{ll}\text { Merah } & \text { : Kekuatan } \\ \text { Biru } & \text { : Keyakinan } \\ \text { Kuning } & \text { : Ceria }\end{array}$

Jika dua warna digabungkan akan menghasilkan kesan yang berbeda:

Merah + Kuning = Oranye

Kekuatan + Ceria $=$ Kesombongan

Merah + Biru $=$ Ungu

Kekuatan + Keyakinan $=$ Kesucian

Kuning + Biru $=$ Hijau

Ceria + Keyakinan $=$ Kasih Sayang

\section{PEMBAHASAN}

Sebelum memetakan psikologi warna yang ada kedalam kombinasi lingkaran warna, warna yang ada pada psikologi warna dari teori Gothe dan Itten terlebih dahulu di sederhanakan menjadi warna primer dan tersier seperti yang terlihat dalam tabel berikut:

Tabel 2. Psikologi warna Goethe

\begin{tabular}{|c|c|c|c|}
\hline Warna & Kesan Positif & Kesan Negatif & $\begin{array}{c}\text { Pengaruh terhadap } \\
\text { Manusia }\end{array}$ \\
\hline Merah & Bermartabat & - & $\begin{array}{c}\text { Menimbulkan efek } \\
\text { semangat }\end{array}$ \\
\hline Kuning & $\begin{array}{l}\text { Cepat, } \\
\text { Ceria }\end{array}$ & $\begin{array}{c}\text { Tidak } \\
\text { menyenangkan }\end{array}$ & $\begin{array}{c}\text { Menimbulkan efek } \\
\text { sukacita }\end{array}$ \\
\hline Biru & $\begin{array}{l}\text { Warna yang } \\
\text { menyenangkan }\end{array}$ & $\begin{array}{l}\text { Dingin, } \\
\text { Melankolis } \\
\text { Gelisah }\end{array}$ & Menimbulkan efek Sedih \\
\hline Oranye & $\begin{array}{c}\text { Hidup, Passion yang } \\
\text { tinggi, Hangat, } \\
\text { Sukacita Kegembiraan }\end{array}$ & Menjengkelkan & $\begin{array}{l}\text { Menimbulkan efek } \\
\text { sukacita }\end{array}$ \\
\hline Ungu & aktif & Rentan, cemas & Menimbulkan efek Sedih \\
\hline Hijau & Tenang & - & Menimbulkan efek Tenang \\
\hline
\end{tabular}

Tabel 3. Psikologi warna Itten

\begin{tabular}{|c|c|}
\hline Warna & Pengaruh terhadap Emosi \\
\hline Merah & Kekuatan \\
\hline Kuning & Ceria \\
\hline Biru & Keyakinan \\
\hline Oranye & Kesombongan \\
\hline Ungu & Kesucian \\
\hline Hijau & Kasih Sayang \\
\hline
\end{tabular}


Dengan menggunakan contoh sebaran warna yang ada pada kombinasi warna color wheels pro pemetaan pengaruh psikologi warna dapat digambarkan pada tabel berikut:

Tabel 4. pemetaan pengaruh psikologi warna

\begin{tabular}{|c|c|c|c|}
\hline $\begin{array}{l}\text { Kombinasi } \\
\text { Warna }\end{array}$ & $\begin{array}{l}\text { Pengaruh Terhadap } \\
\text { Manusia (Goethe) }\end{array}$ & $\begin{array}{c}\text { Pengaruh } \\
\text { terhadap } \\
\text { Emosi } \\
\text { (Itten) }\end{array}$ & Kesimpulan \\
\hline Split & $\begin{array}{l}\text { (Kombinasi Kuning, Biru dan } \\
\text { Hijau) } \\
\text { Kesan Positif: } \\
\text { Cepat, Ceria, Warna yang } \\
\text { menyenangkan, Tenang } \\
\text { Kesan Negatif: } \\
\text { Tidak menyenangkan, } \\
\text { Dingin, } \\
\text { Melankolis } \\
\text { Gelisah, Tenang }\end{array}$ & $\begin{array}{l}\text { (Kombinasi } \\
\text { Kuning, Biru } \\
\text { dan Hijau) } \\
\text { Ceria, } \\
\text { Keyakinan, } \\
\text { Kasih } \\
\text { Sayang }\end{array}$ & $\begin{array}{l}\text { Dari dua pengaruh yang } \\
\text { disampaikan oleh Goethe } \\
\text { dan Itten, kesan yang } \\
\text { ditimbulkan dari kombinasi } \\
\text { Split complementary } \\
\text { adalah keceriaan, kasih } \\
\text { sayang dan rasa tenang } \\
\text { untuk dampak positif } \\
\text { sedangkan Dingin, gelisah } \\
\text { dan melankolis untuk } \\
\text { dampak negatif }\end{array}$ \\
\hline & $\begin{array}{l}\text { (Kombinasi Kuning, Hijau dan } \\
\text { Ungu) } \\
\text { Kesan Positif: } \\
\text { Cepat, Ceria, Tenang, aktif } \\
\frac{\text { Kesan Negatif: }}{\text { Tidak menyenangkan, }} \\
\text { Tenang, Rentan, cemas }\end{array}$ & $\begin{array}{l}\text { Kombinasi } \\
\text { Kuning, Hijau } \\
\text { dan Ungu) } \\
\text { Ceria, } \\
\text { Kasih } \\
\text { Sayang, } \\
\text { Kesucian }\end{array}$ & $\begin{array}{l}\text { Dari dua pengaruh yang } \\
\text { disampaikan oleh Goethe } \\
\text { dan Itten, kesan yang } \\
\text { ditimbulkan dari kombinasi } \\
\text { Triadic adalah Ceria, Aktif, } \\
\text { kasih sayang dan kesucian } \\
\text { untuk dampak positif } \\
\text { sedangkan cemas dan } \\
\text { rentan untuk dampak } \\
\text { negatif }\end{array}$ \\
\hline $\begin{array}{l}\text { Tetradic (double } \\
\text { complementary) }\end{array}$ & $\begin{array}{l}\text { (Kombinasi Merah, Kuning, } \\
\text { Hijau dan Ungu) } \\
\text { Kesan Positif: } \\
\text { Bermartabat, Cepat, Ceria, } \\
\text { Warna yang } \\
\text { menyenangkan, Tenang, } \\
\text { aktif } \\
\text { Kesan Negatif: } \\
\text { Tidak menyenangkan, } \\
\text { Dingin, } \\
\text { Melankolis } \\
\text { Gelisah, Tenang, Rentan, } \\
\text { cemas }\end{array}$ & $\begin{array}{l}\text { (Kombinasi } \\
\text { Merah, } \\
\text { Kuning, Hijau } \\
\text { dan Ungu) } \\
\text { Kekuatan, } \\
\text { Ceria, } \\
\text { Kasih } \\
\text { Sayang, } \\
\text { Kesucian }\end{array}$ & $\begin{array}{l}\text { Dari dua pengaruh yang } \\
\text { disampaikan oleh Goethe } \\
\text { dan Itten, kesan yang } \\
\text { ditimbulkan dari kombinasi } \\
\text { Tetradic (double } \\
\text { complementary) adalah } \\
\text { Bermartabat dan kuat, } \\
\text { Ceria, Aktif, kasih sayang } \\
\text { dan kesucian untuk } \\
\text { dampak positif sedangkan } \\
\text { Dingin, Melankolis, cemas } \\
\text { dan gelisah serta rentan } \\
\text { untuk dampak negatif }\end{array}$ \\
\hline
\end{tabular}


Dari kesimpulan yang ada bila diteliti dengan menggunakan website dengan kombinasi warna yang sama, maka akan memberikan pengaruh yang sama terhadap user / pengguna website tersebut.

Berikut contoh dari beberapa website yang menggunakan warna Split complementary, Triadic, Tetradic (double complementary) [10].

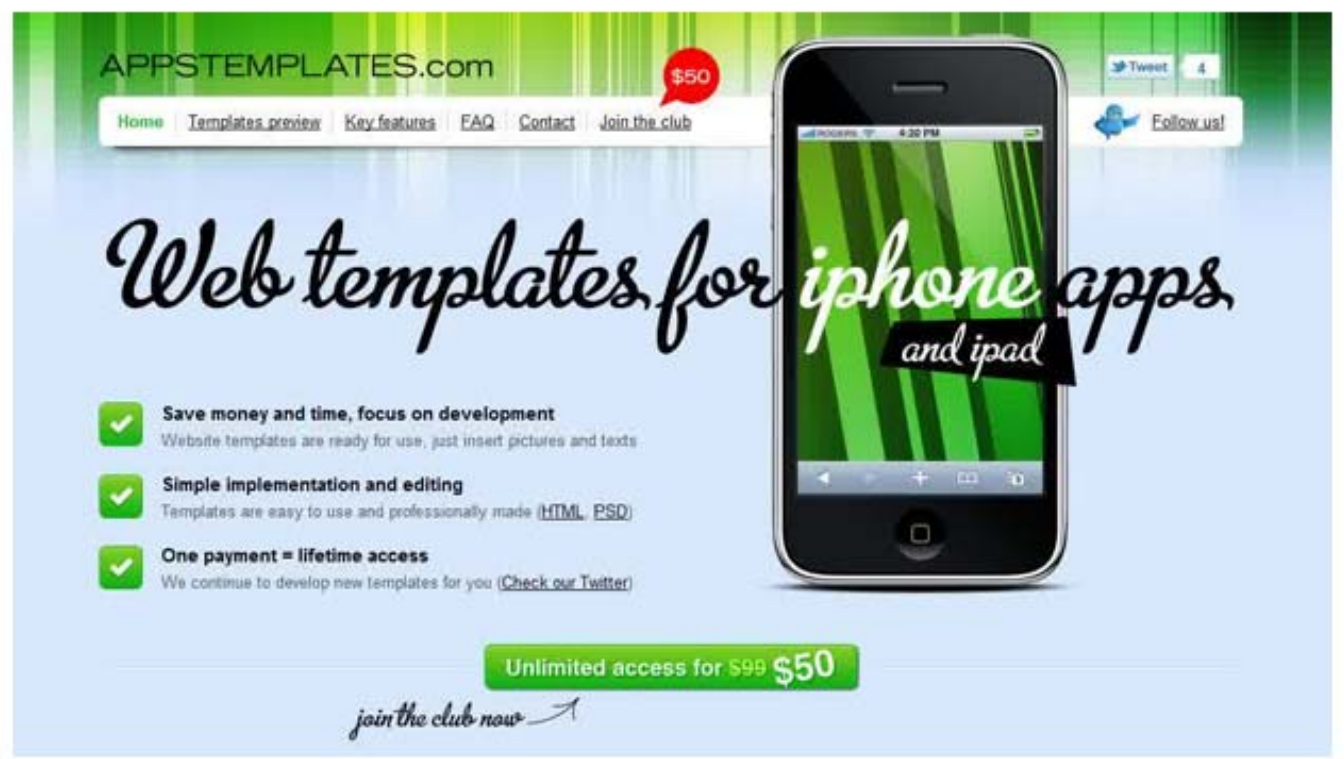

Gambar 5. contoh website yang menggunakan warna Split complementary

Website pada gambar 5 menggunakan warna split complementary, warna-warna yang digunakan adalah warna merah, biru dan hijau. Warna-warna tersebut memberikan kesan yang tenang, menyenangkan dan kuat.

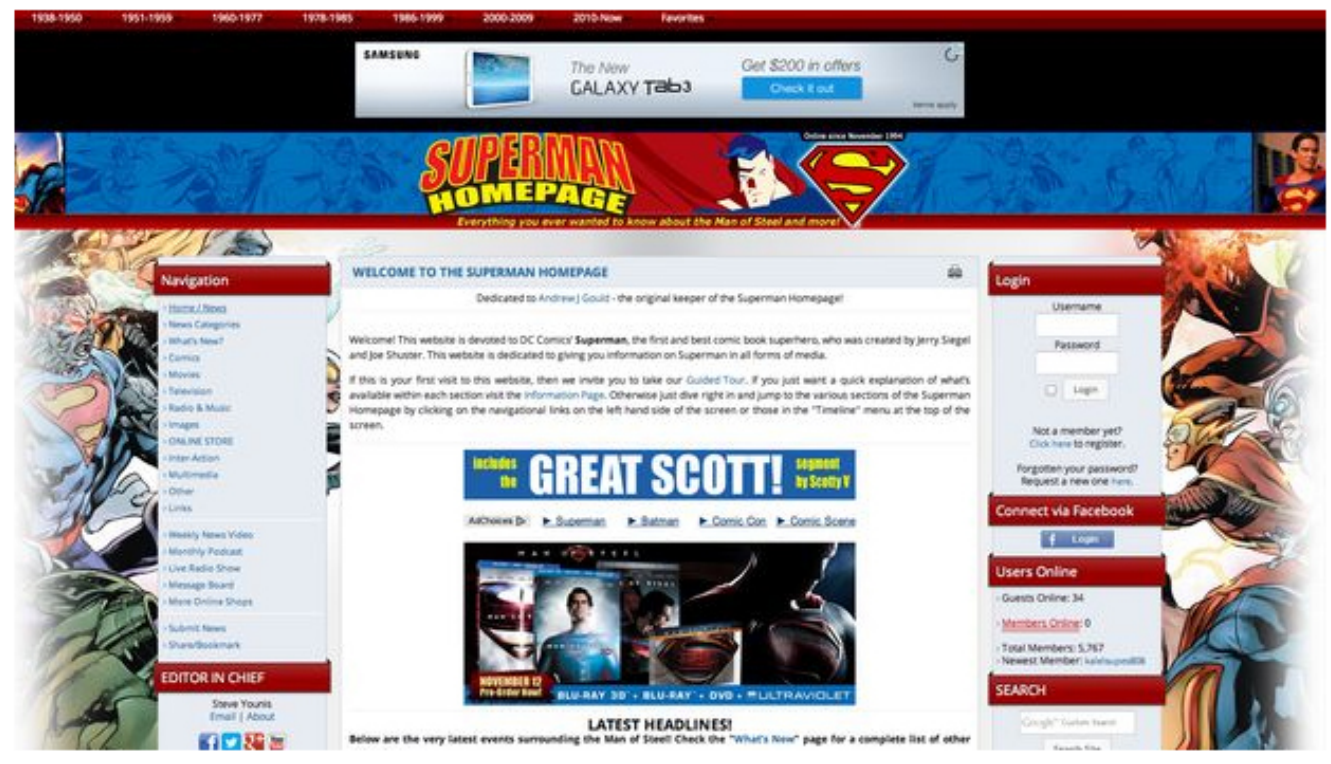

Gambar 6. contoh website yang menggunakan warna Triadic 
Website pada gambar 6 menggunakan warna split complementary, warna-warna yang digunakan adalah warna merah, biru dan Kuning. Warna-warna tersebut memberikan kesan yang Kuat, Tenang dan suka cita.

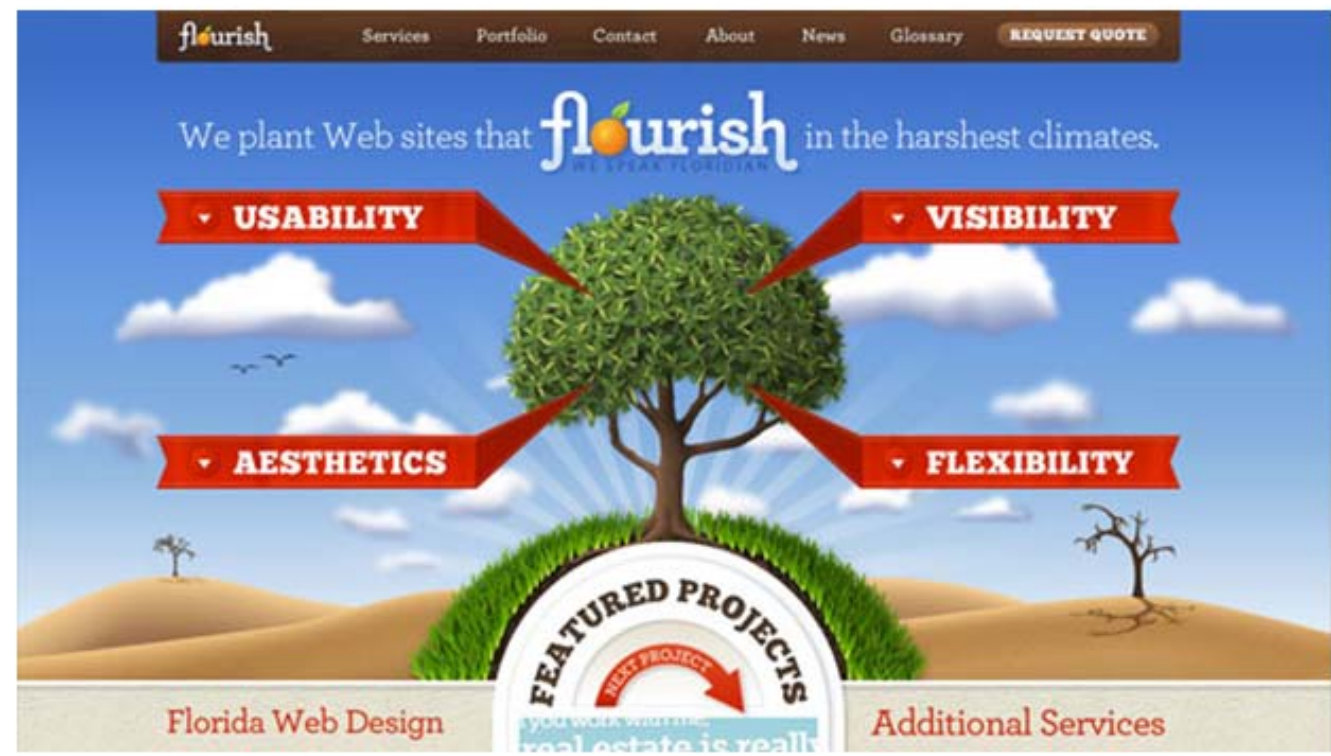

Gambar 7. contoh website yang menggunakan warna Tetradic (double complementary)

Website pada gambar 7 menggunakan warna split complementary, warna-warna yang digunakan adalah warna merah, biru, hijau dan orange. Warna-warna tersebut memberikan kesan yang tenang, menyenangkan, kuat dan ceria.

\section{KESIMPULAN}

Dari dua pengaruh yang disampaikan oleh Goethe dan Itten, kombinasi warna dapat memberikan kesan yang ditimbulkan. Kombinasi Split complementary adalah keceriaan, kasih sayang dan rasa tenang untuk dampak positif sedangkan Dingin, gelisah dan melankolis untuk dampak negatif, kesan yang ditimbulkan dari kombinasi Triadic adalah Ceria, Aktif, kasih sayang dan kesucian untuk dampak positif sedangkan cemas dan rentan untuk dampak negatif dan kesan yang ditimbulkan dari kombinasi Tetradic (double complementary) adalah Bermartabat dan kuat, Ceria, Aktif, kasih sayang dan kesucian untuk dampak positif sedangkan Dingin, Melankolis, cemas dan gelisah serta rentan untuk dampak negatif. 


\section{DAFTAR PUSTAKA}

[1] L. Holtzschue, Understanding Color and Introduction for Designer, 4 ed., New Jersey: John Wiley \& Sons, Inc., 2011.

[2] R. D. Pratama, I. Suyadi and S. Heru , "Persepsi User Terhadap Desain Website ecommarce (Studi Pada Pengguna Website JKM Store)," Jurnal Administrasi Bisnis (JAB), vol. 9, 2014.

[3] C. Krischer, "Color Considerations for Web Usability," International Journal of Color Computing, 2010.

[4] B. Edwards, Color : a course in mastering the art of mixing colors, USA: Jeremy P. Tarcher/Penguin, 2004.

[5] J. Beaird, The Principles of Beautiful Web Desain, Second ed., Canada: SitePoint Pty Ltd, 2010.

[6] D. Y. Kim, "The Interactive Effects of Colors on Visual Attention and Working Memory: In Case of Images of Tourist Attractions," in International CHRIE Conference-Refereed Track, 2010.

[7] "Basic Color Theory," [Online]. Available: http://www.color-wheel-pro.com/colortheory-basics.html. [Accessed 0110 2015].

[8] N. A. Nijdam, "Mapping emotion to color".

[9] J. Itten and F. Birren, The Elements of Color, New York: John Wiley \& Son, Inc, 2003.

[10] Apri, "Color Scheme Theory and Psychology for Designers," 24 December 2014. [Online]. Available: http://www.apriwd.com/web-design/color-scheme-theoryand-psychology-for-designers/. [Accessed 05 October 2015]. 
Andharupa, Jurnal Desain Komunikasi Visual \& Multimedia. Vol.01 No.01 Tahun 2015 